\title{
Research on the Innovation Method of College English Teaching Based on Internet
}

\author{
Xu Rui \\ School of Foreign Studies, Xi'an University, 710065 \\ Keywords: Internet; College English; Teaching; Innovation \\ Abstract: The Internet has become an irreplaceable part of our work and life. In recent \\ years, the Internet has penetrated into every aspect of our work and life. The Internet is a \\ brand new platform that provides conditions and possibilities for innovation and \\ development in all walks of life. The Internet also has a great and profound impact on \\ education and teaching. At present, the development of higher education in China has \\ entered a new stage. In the new era of education and teaching reform and development, \\ how to do a good job of Internet-based college English teaching innovation has become a \\ realistic problem that teachers in the industry have to face.
}

\section{Introduction}

English is a special course. What make it special is, first of all, its special status. Under the wave of globalization, every country has to exchange and cooperate with other countries. As one of the languages of official communication, English has an important position in the international arena. Secondly, English is very practical. The improvement of English ability should not only stay in the mastery of basic knowledge, but more should be reflected in the practical application of English. In recent years, China's emphasis on English teaching has been continuously improved, and college English teaching has achieved great achievements in many aspects. However, there are still many problems that cannot be ignored.

\section{Problems Existing in the Teaching of College Literature Courses}

The problems existing in the teaching of college literature courses can be summarized as the following points.

\subsection{Simple understanding of the Teaching Process}

What kind of process is teaching? How should we correctly understand this process? Different people have different views of this question. However, no matter how the teaching process is known, if the effect of education and teaching is not compatible with the requirements of talent training, then there must be certain problems in this understanding. At present, a big misunderstanding in college English teaching is that the understanding of the teaching process is not profound enough. Many teachers regard college English teaching as a process of knowledge interpretation. Teachers 
who have this kind of understanding lack comprehensive and meticulous understanding of college English courses, regard college English as the accumulation of knowledge points, neglect the rich connotation of college English courses, and completely separate human characteristics and knowledge. This kind of understanding has profound historical and social roots. Especially in recent years, as business activities continue to infiltrate into campus life, many college teachers have misunderstood their thoughts and understandings. They have insufficient understanding of the public welfare and social attributes of teaching activities, and regard teaching as a process of knowledge interpretation. At the same time, due to institutional reasons, the knowledge structure of English teachers in colleges and universities in China is generally relatively simple, and their knowledge makes them easy to misunderstand education and teaching.

\subsection{Utilitarian trend in Teaching Objective}

In recent years, influenced by some big environments, people's thinking patterns are very susceptible to commercialization and utilitarian influence. On campuses, the impact of this trend of thought is not uncommon. For example, the primary criterion for students to evaluate the quality of a subject is whether the subject will be able to find a job in the future, and what kind of future the subject can bring to them. With this kind of mentality to learn, students naturally have no interest in the course itself. There are still some students who study for the exam. They are used to taking notes in class, rote before the exam, and forgetting everything after the exam. Extracurricular reading is an important part of learning English well and an indispensable way to learn English. But unfortunately, the current English reading of college students in China is generally at a low level. This situation is not unique to individual institutions, but is a common problem in college English teaching.

\subsection{Overall Backwardness of the Textbook System}

The textbooks of college English courses in China are generally theoretical. Many scholars have carried out extensive and in-depth research on this issue, and have made some explorations in theory and practice, and achieved very good results. At present, college English textbooks are basically based on knowledge points. This mode violates people's rules of understanding and the rules of education and teaching. Due to the influence of history and system, the knowledge of humanities in English majors in China is generally lacking. Therefore, many students can only understand a little the knowledge in the textbooks. They can't fully understand English knowledge from the perspective of culture and other aspects. We are not denying the importance of theoretical knowledge, but we cannot let the theoretical content and system constrain the motivation of students' learning. The charm of English itself is affected, which affects the enthusiasm and initiative of students.

\subsection{Without a Scientific Assessment System}

At present, the college English assessment system we use is not tailor-made for English majors, but it follows the traditional test-taking mechanism to serve the exam-oriented education. Such an assessment system is neither reasonable nor scientific, and has been widely criticized. The impact of this assessment mode on students' English learning is negative, which will let students' English learning one-sided. Currently, the traditional assessment system is used the most widely in the assessment of English students, and it also needs to be changed the most urgently. 


\subsection{Less improvement of Teachers' Overall Literacy}

What kinds of abilities are needed for college English teachers? What kind of teacher is a good teacher? Different people have different views of this question. As far as college English is concerned, a good English teacher must have a more comprehensive knowledge system first, and meanwhile have their own methods and insights on how to do a good job in college English teaching. As a kind of social science, English is undoubtedly a concise and sublimation of life. It is a comprehensive refinement of all the components of life. Therefore, English learning itself is more complicated. It requires teachers to have a strong comprehensive quality. Another point is that, in China, many English teachers in colleges and universities are English major, but they are not graduates of normal colleges and universities. Therefore, there are certain deficiencies in education and teaching. Many teachers are full of knowledge, but they are unable to perform in teaching. The problem of a low overall literacy of the teaching staff is not only an educational issue, but also a social issue. How to improve the overall quality of teachers in the industry is an urgent issue that the whole society has to face.

\section{Internet-based English Teaching Innovation in Colleges and Universities}

The current trend of global education reform is to focus on the individuality of the individual being educated, to carry out personalized education that suits individual characteristics, and to emphasize the individualized development of students. This has something in common with the quality education advocated by China at present. At present, multimedia applications are widely used. These are just the most basic applications of education and teaching under the conditions of information and internet. As far as multimedia courseware is concerned, although it is only a simple application, it greatly enhances the classroom capacity of teachers, so that teachers can present rigid teaching content in front of students in a combination of sound and image.

Internet-based education and teaching and traditional education and teaching complement each other. The traditional teaching mode takes the teacher as the core and supportting point of education and teaching. The teacher lectures and the student listen. Education and teaching under the Internet conditions can separate learning from teaching in form. Students' learning and teachers' teaching is no longer limited by time and place, and the form of education and teaching has been greatly expanded. There are still many improvements in the education and teaching mode under the Internet conditions, such as WeChat public account and MOOC. It is necessary to emphasize that the view that the teacher's function is weakened under the Internet conditions is extremely wrong. The author personally believes that under the Internet conditions, the function of teachers needs to be strengthened. Under the conditions of the Internet, higher requirements are placed on the ability and quality of teachers.

Internet-based English teaching innovation in colleges and universities should focus on the following aspects.

\subsection{Redefining Teaching and Learning}

Under the conditions of the Internet, the relationship between teaching and learning has become very subtle. This is because under the conditions of the Internet, the traditional teacher-centered teaching method has been subverted, and the students' initiative in learning has been strengthened. Many courses can even be carried out entirely on students. Teachers only need to grasp the progress and general direction of education and teaching in the English course. Under the conditions of the Internet, the teaching interaction between teachers and students is enhanced. Students who encounter problems that they do not understand can directly ask questions to teachers in the form of 
online questions. Teachers can solve problems and doubts in students' learning in a timely manner through online questions and answers. At the same time, under the conditions of the Internet, students can easily obtain learning materials, which can be obtained from the Internet or from the material library compiled by the teacher. Through the Internet teaching mode, the initiative of students' learning has been greatly improved. At the same time, this learning method can effectively practice students' independent thinking ability. In the Internet and multimedia environment, the content of English teaching presents a diversified trend in expression. Students can understand the content of English learning through multimedia, animation, audio, comics, etc., which breaks the limitations of traditional English learning. It can not only let students choose the learning style that they like, but also add fun to study, which is indispensable for improving the initiative of students.

\subsection{Enhancing Students' Humanistic Literacy}

For English majors, humanistic literacy directly affects the students' comprehensive ability. Humanistic literacy has a subtle influence on the improvement of students' overall English ability. Because this process is relatively concealed, it is often overlooked. The so-called humanistic spirit is a value orientation based on the concern of the people themselves and taking into account the human beings' common survival and development interests. The humanistic spirit is the sum of the spiritual culture formed by the spiritual accumulation of human beings and precipitation. The humanistic spirit is manifested through humanistic literacy. Traditional college English courses are limited to the teaching of knowledge, focus on the realization of specific teaching purposes, and ignore students' self-development and humanities education. In the traditional college English education, due to the limited classroom conditions and the certain length of each course, even if teachers have relevant knowledge reserves, many lectures on the humanities can only be skimmed through. There is no way to fully expand. The cultivation of students' humanistic spirit can be said to be the most basic educational goal of college English courses, and it is also in line with the needs of the comprehensive development of individual students. Today, in advocating quality education, we attach great importance to the cultivation of students' humanistic spirit. In recent years, many experts in English education have explored and studied how to improve the English proficiency of college students. Through their own practice, they have revealed the important role of humanistic spirit in promoting English learning. How to design a humanities material library that is in line with the actual application of the school in combination with the Internet is a direction that every university should strive to explore and work hard.

\subsection{Strengthening Students' Practical Ability}

Under the Internet conditions, it has become easier to design student learning and practice links. The advantage of the Internet is to break the limits of time and space. Under the Internet conditions, students can conduct online discussion and other teaching practices. The current campus network environment can fully support video conferencing and multi-party video calls. Through a variety of communication activities, students can easily inspire learning in the collision. At the same time, this way can also train students' communication skills and cultivate students' team awareness. Of course, there are still many practical aspects that we can design under the Internet conditions. For example, the human-machine dialogue between the Internet and artificial intelligence. In the end, which method can be used should be based on the teaching conditions and students' preferences. Besides, colleges should create a good atmosphere for literature learning for students with the support of technical means. 


\section{Conclusion}

Internet-based college English teaching is an important content and direction of future English teaching reform. As a college English teacher, we should recognize the situation, attach great importance to the mind, do a good job of reform of college English teaching with the sense of responsibility and mission, and promote the healthy development of college English.

\section{References}

[1] Xiang Ligang. "Internet +" Is not A Simple Addition of Traditional Industries and the Internet [J]. Sales and Marketing (Channel Edition), 2015, (04).

[2] Wang Minghua. Research on College English Teaching Model Based on Internet [J]. Journal of Huaihai Institute of Technology (Social Science Edition), 2011, (23).

[3] Xiong Wei and Liu Dehua. Discussion on the Strategies of College English Interactive Teaching under the Background of Internet [J].English Teachers, 2016(23).

[4] Wang Hongyang. College English Classroom Teaching under the Background of "Internet +": An Analysis Based on MOOC, Micro-Course, and Flipping Classroom [J]. China Training, 2016(20).

[5] Wang Hongxia. The Practice and Effect of College English Teaching Reform under the Background of "Internet +"[J].English Square, 2016(8).

[6] Jiang Lili. Exploring the English Teaching Model of Colleges and Universities under the Background of Internet [J]. Art Science and Technology, 2016(6). 